WORKING PAPER NO. 6

Jan 1995

\title{
A Conceptual Framework for CIFOR's Research on Non-Wood Forest Products
}

\author{
Manuel Ruiz Pérez
}

\begin{abstract}
Summary
M ost NWFPs research is site specific and sectoral, thus reducing its potential value for policy analysis and development actions. The main challenge for future research is to develop general frameworks within which to structure dispersed studies and to transform them into useful policy- and actionguiding instruments. In the first part of the paper three types of mutually supporting framework are proposed: functional typologies of extractive economy situations, general theories and models.

The second part of the paper analyses the complexity of extractive economies from a dynamic perspective, exploring some trends and hypotheses. Six major dynamic dimensions are considered: forest-woodland dynamics; non-market - market dynamics; technological changes: use of labour . household economy; peoples perceptions, preferences and opportunities - cultural dynamics; and policy development. Finally, the paper proposes a hypothetical model of the global trend for NWFP with a renewed, multifunctional role linked both to their physical properties as well as to their new social, cultural and environmental attributes.
\end{abstract}

CENTER FOR INTERNATIONAL FORESTRY RESEARCH

office address: Jalan Gunung Batu5 Bogor 16001 Indonesia mailing address: P.O. Box 6596, JKPWB Jakarta 10065 Indonesia tel.: +62(25 1) 34-3652 fax: +62(25 1) 32-6433

email: cifor@cgnet.com 


\section{The CGIAR System}

The Consultative Group on International Agricultural Research (CGIAR) is an informal association of 41 public and private sector donors that supports a network of sixteen international agricultural research centers, CIFOR being the newest of these centers. The Group was established in 1971. The CGIAR centers are part of a global agricultural research system which endeavor to apply international scientific capacity to solution of the problems of the world's disadvantaged people.

\section{CIFOR}

CIFOR was established under the CGIAR system in response to global concerns about the social, environmental and economic consequences of loss and degradation of forests. It operates through a series of highly decentralized partnerships with key institutions and/or individuals throughout the developing and industrialized worlds. The nature and duration of these partnerships are determined by the specific research problems being addressed. This research agenda is under constant review and is subject to change as the partners recognize new opportunities and problems. 


\title{
A Conceptual Framework for CIFOR's Research on Non-Wood Forest Products
}

\author{
Manuel Ruiz Pérez ${ }^{1}$
}

\begin{abstract}
Summary
Most NWFP reseurch is site specific and sectoral, thus reducing its potential value for policy analysis and development actions. The main challenge for future research is to develop genera; frameworks within which to structure dispersed studies and to transform them into useful policy-and actionguiding instruments. in the jirst part of the paper three types of mutually supporting framework are proposed: functional typolbgies of extractive economy situations, general theories and models.

The second part of the paper analyses the complexity of extractive economies from a dynamic perspective, exploring some trends and hypotheses. Six major dynamic dimensions are considered: forest-woodland dynamics; non-market - market dynamics; technological changes: use of labour household economy; people's perceptions, preferences and opportunities - cultural dynamics; and policy development. Finally, the paper proposes a hypothetical model of the global trend for NWFP with a renewed, multifunctional role linked both to their physical properties as well as to their new social, cultural and environmental attributes.
\end{abstract}

\section{Purpose of the conceptual framework,}

A strategic objective for an institution such as CIFOR, with a worldwide research mandate, is to develop global pictures that can help us to understand the present situation, the dynamic forces and the evolutionary trends of world forests. This is necessary in order to formulate coherent policy proposals. Two conditions are needed to develop such global perspectives:

a) Sufficient representative cases/situations.

b) Broad-based information, which is collected and analysed using compatible methodologies and producing comparable results.

The purpose of this paper is to advance ideas that may help to establish the foundations to meet both the above conditions in the case of Non-wood Forest Products (NWFP). A general survey of the research situation will be presented and ways, towards achieving generalizable outcomes will be proposed. It will then give an overview of the major dynamic forces and evolutionary trends which intluence NWFP and pose some key questions concerning research hypotheses and implications. The paper is meant to illustratethe scope of generalizable outcomes, while at the same time exploring some elements of potential interest for their preparation.

The next step will be to focus on each of the major, inter related dynamic forces and evolutionary trends identified. This would be done by selected experts and could lead to a workshop and publication. The workshop would ddvelop a compatible research protocol that, after distilling the major issues, trends, questions, research hypotheses and theories, could be used for comparative study on different sites.

Field implementation should normally benefit from the experience of already established teams, which constitutes the core of our knowledge about NWFP. One objective of this total process is to reinforce these experiences by trying to develop ways of expanding on-going research into complementary arcas of potential interest based on the dynamics of NWFP worldwide. Comparative analysis of data from different environmental and socio economic conditions

\footnotetext{
${ }^{1}$ Senior Scientist, Center for International Forestry Research (CIFOR), P.O. Box 6596, JKPWB, Jakarta 10065, Indonesia.
} 
could help to develop typologies, theories and models based on these dynamics to direct future research and policy development.

While carrying out research to support the general theories and models, the enlarged and comprehensive nature of the studies would hopefully produce results which are relevant for the development of the communities who use these resources. Thus, a two-way, dialectic approach between the specific research outputs and the global framework could be established.

Statement of the problem:

The evolution of forest-based, extractive activities is highly variable and uncertain. Poor anticipation of changes can impact negatively on the development process. CIFOR believes that there are common threads und dimensions in the dynumics of NWFP development that can help to identify some of these changes. However most research is carried out on a casestudy basis, and without an evolutionary perspective, which does not identifjr these common threads or anticipate trends. Consequently, policies and development actions are being taken in an isolated context, without a clear idea of their interactions or full implications. Therefore unexpected, and sometimes unwanted, results occur; resources are wasted and opportunities are lost.

\section{Overview of the present research situation}

Since the Second World War, attention has centred on the production capabilities of forests, and particularly in tropical forests, on timber production. The actual and potential role of NWFP as well as the environmental services have been left aside. In recent years, a new view of the issue has emerged that tries to value NWFP and to understand their role in the life of the people,' in the market and in the forest economy as a whole. An increasing amount of research and literature has been produced, particularly in the last 15 years, to support and promote this approach. Pressures to conserve forests and to use them sustainably have also contributed to the renewed interest. A wide range of environments, from almost every tropical country, has been studied with different focuses and disciplinary perspectives.

Some comprehensive and integrated research has been carried out by research teams or reviewed at international meetings: for Central America (CATIE, 1992 and various working papers of the CATIF-OLAF0 project); for several parts of the Amazon Region (Lescure et al., 1993; Anderson, 1990); for West Africa (Falconer. 1990); for South East Asia (de Beer and McDermott, 1989). However, most research has been carried out at a local level. and from one or more of three main perspectives:
- Commodity/income/market-driven focus

- People's perceptions/traditional knowledge/household needs focus

Biological properties/sustainable management focus

These correspond, in general terms, with the professional expertise of the economist, the anthropologist/rural sociologist and the biologist/ecologist/forester. Some complementary areas of interest have also been pursued. The evaluation of non-marketed products and environmental services, technological improvements in the extraction, processing, storage and distribution, or historical research of past uses and trends are all issues studied.

The practical results and proposals arising from these sectoral, normally synchronic and locally based studies sometimes fail to incorporate the interactions of forest with nonforest policies. On the other hand, a comprehensive study may lack comparisons with experiences in other countries, which could limit its value for policy development. In other cases, NWFP with similar properties may be promoted without a complete understanding of the impacts of regional or international market competition.

The need for comparative studies in different regions of the world has been advanced by severalauthors (for example, Peluso, 1992; Ctxloy \& Bawn, Ruiz 
Perez et al.. 1993; Salafsky et al., 1993). However, the differences in methodology, scope, range of interest and depth of research have prevented formation of a global view of the current situation and evolutionary trends in this very complex and dynamic sector. Such an overview is particularly important at the present time when rapid action is required, and could play a major role in guiding the development of new techniques and policy proposals.

The first attempts to obtain a comprehensive picture of NWFP date back several decades and followed a "catalogue approach", listing plants and their uses from different parts of the world (for example, Heyne, 1927, cited by de Wit, 1994; Burkill, 1935). Admittedly, this is a first basic step on which to build, and is still very far from completion (see the efforts being currently undertaken by projects like PROSEA for South East Asia or the University of BrasiliaIBAMX for the Brazilian Amazon). Studies of sectors like chemical products, fibres and market information have also been conducted. However, this is still insufficient to understand the complex relationships between people and products and their evolutionary trends, and particularly their diachronic properties and evolution. The few global-level comparative reviews which have been conducted (for example, Townson, 1994) and these remain inconclusive. This reduces their value for research, technology and policy proposals which aim to improve the chances of sustainable development for the people, usually poor segments of the rural populations, who depend on those resources. It is also insufficient to widen the still-narrow focus used to assess the conservation values of forests that can offer a sustainable yield of products and environmental services.

\section{Towards generalizable results}

The very complex universe of NWFP retlects high variability and site speciticity. To date, this has prevented a global view. Consequently, most activities remain unrelated and policy proposals and development actions are made without the necessary understanding of their full implications. The main challenge for future research on NWFP is the development of general frameworks within which to structure the dispersed studies and to transform them into useful policy- and action-guiding instruments. There are three main types of mutually supporting frameworks: typologies, theories and models.

\section{Expected output:}

Typologies of situations general theories and models to understand the interrelations and dynamic trends of different estractive economies and people. These would guide research, policy proposals and developmettt actions. This could focus activities and increase the potential oj' NWFP as a significant element in rural poverty alleviation and general development, thus helping to avoid possible negative impacts.

\section{Reference to CIFOR's Medium Term Plan:}

The expected output directly relates to the following ClFOR Medium Term Plan activities:
I.3. Adoption of policy change.
I.4. Employment and income from forests.
2.2. managgement for \&diversity and diverse products.
4. I. management for NWFP by local communities.
4.3. Market requirements and possibilities for underused NWFP

\section{Functional typology}

Until now, the most commonly used typology is different categories of products (like tibers, leaves. fruits, resins). of little use for purposes other than as statistics. Functional typologies that retltxt the high variability dynamism are yet to be developed. In fact, it could be argued that what is needed are typologies of extractive economy situations rather than NWF products. Some of their main features could include: 
Use of dynamic properties as policy and action orientation criteria.

- Discrimination between different evolutionary trends.

Multidimensional vaiiables/descriptors.

- $\quad$ Based on a reduced set of biophysical and socioeconomic attributes.

- Hierarchical structure.
One of the main contributions of CIFOR to this field, and one of the main outcomes of the present proposal, would be to make progress on the preparation of these typologies. It would probably follow an iterative process by which some crude, general situations can be initially identitied. These situations will be characterised by their trends and the factors promoting/affecting them. Each situation will then be subdivided into more detailed groups. Improvements in knowledge will refine the model.

The following example is only an illustration of this iterative process:

I.- Situation of general decline

2.- Situation stable or slightly declining, with major disfunctionalities $=>$

3.- Situation stable or slightly improving, with some bottlenecks

4.- Situation of expansion on main fronts

2. I .- Mainly environmental disfunctionalities $=>$

2.2.- Mainly socioeconomic disfunctionalities

2.3.- Both disfunctionalities equally important

2. I. I.- depletion in a context of good market potential

2.1.2.- Non-destructive exploitation unable to meet demands

2.1.3.- Depletion in a context of low market potential

\section{General theories}

Attempts to develop general theories to explain observed situations and trends in the use of NWFP have been made from different perspectives. Although a comprehensive review is outside the scope of this paper, an outline of some major approaches will show their variability. Cultural ecology, based on postulates of evolutionary ecology, has developed a series of adaptationist theories to explain the patterns of resource consumption, especially in indigenous communities. Their basic assumption is that people adapt their culture to the constraints of the natural environment. Optimum foraging theory is the most widely known (Hames and Vickers, 1983). Management theories, on the other hand, have cri ticised this approach, emphasising the proactive role of people in shaping the forest to their needs, overcoming some of the environmental limitations (Balée, 1989).

Development theories, which have been proposed lo explain some trends in the use ot
NWFP, see extractivism as a sub-optimal situation derived from social limiting factors (lack of culture and technology training, low capital availability, poor access to market; Godny and Bawa, 1993). Dependence on NWFP should decrease as individuals and/or communities move along this path of development. Sometimes microeconomic models (using linear regressions) are adopted in order to validate rather than to predict (see Godoy et al., 1994; Gunatilake, 1994). A particularly intluential expression of this spproac $h$ is represented by agronomical development theory, that sees the trend towards domestication of the species which produces the successful commodities as the ultimate, unavoidable end to wild gathering (Homma, 1990, 1992).

Theories to explain the use of NWFP based on household livelihood strategies (optimal use of Iabour, risk aversion, access to resources, etc.) have also been developed (see review of Falconer and Arnold, 1989). interesting attempts have been made to link 
them to the joint energy-economic balance of the activity in order to compare extraction versus agricultural options (Pereira, 1992).

Some of these theories represent important steps in the generalisation process. However, although they may be locally applicable, they remain inconclusive or face conflicting evidence at a more aggregated level. This attests to the difficulty of the task of developing gerneralisable results, bu t a 1 s o highlights the need to make research progress in that direction.

\section{Models}

Models are abstractions of the reality used to assist understanding. As such they have advantages (reduced number of elements to consider, help to understand complexity, experimentation at low cost and risk 3 but also disadvantages (possible oversimplification, restricted validity and applicability). As noted above, microeconomic models have been used to support some developmental theories of NWFP. Similarly, cultural ecology theories have also used models to check the validity of their assumptions (for examples, see Hames \& Vickers, 1953). These models tend to be descriptive and deterministic, thus reducing their scope for policy analysis and proposals. There are some general rules of model formulation and use, particularly in the tieid of policy (Bossei \& Bruenig, 1992): statement of the 'purpose; explanation of limitations; separation of objective facts from assumptions; full documentition and transparency; proper validation.

Models can have three main roles in the policy process (King and Kraemer, 1993): to clarify the issues in debate; to improve consistency and discipline of analysis and discourse; and to provide a relevant and powerful form of advice, especially on undesirable results. These are precisely the roles envisaged for the types of models advocated in this paper. In order to fulfill these roles, they should share some of the following characteristics (Bossei and Bruenig, 1992; Botkin, 1993):

- Explanatory: use a representation of real system structure to describe system behaviour.

- Stochastic: parameters or relationships may change stochastically within given limits.
- Use both quantitative and qualitritive expressions.

- Use different scenarios to incorporate important exogenous inputs.

The next part of this paper attempts to analyse the complexity of extractive economies from a dynamic perspective. It will explore some trends and hypotheses, as well as illustrate possible outcomes by use of the oeneraiizable results postulated above. It is also intended as an exploration of elements of potential interest in the development of typologies, theories and models.

\section{Major dynamic factors influencing the evolution of extractive economies}

A preliminary view of the evolutionary trends of extractive economies shows some major driving dynamic forces. They are not fully independent, showing different degrees of interaction. We should also bear in mind that in people's views and daily experience they are not necessarily separated. Their significance varies from place to place according to environmental and socioeconomic conditions. It can also change over time as the situation in one place changes. In fact, this space/time variation is probably the only element common to all trends. They can be divided into six major axes or dimensions of dynamic variation (the order is not related to their importance):

- Forest - woodland dynamics

- Non-market - market dynamics

- Technological changes

- Use of labour - household economy

- People's perceptions, preferences and opportunities - cultural dynamics

- Policy development

Some of the dimensions may be bipolar, while others can be multipolar. Their range of variation is shown by cases at the extreme positions on the spectrum. Similarly, the trends may follow a dominant path combined with secondary processes in opposite directions. Consequently, different situations may coexist for a long period despite having a strong, dominant trend. Identifying the conditions that favour certain situations versus 
those that render others obsolete is one of the crucial factors in policy design for and promotion of NWFP.

It should be remembered at this point, that the research hypotheses proposed are formulated at a very general level, being meant as framework hypotheses rather than field-test hypotheses, and that they are by no means exhaustive. In order to make them operational, a priority setting for questions and hypotheses (with definitions and a full, detailed development) will have to be implemented during the s'econd step. Finally, the hypotheses presented are not necessarily coincident with my own views and they may correspond to prevalent views that need to be challenged.

\section{Forest-woodland dynamics}

Forests are rapidly changing across the tropics. Some activities, like logging and slash-and-burn agriculture with long fallow periods, lead to secondary forests. These may be enriched with species of interest (normally plants) through conscious (planting, protecting some trees from hazards or unwanted competition) or involuntary (spreading seeds while harvesting, opening more favourable environments) actions. In other cases an anthropogenic-forest type ecosystem may be established (jardin de cases home gardens). Finally, some forests are replaced by tree plantations for timber, food, latex, etc. The direction of change is from primary to secondary forests and tree plantations, following a general path of low reversibility in the medium term (Fig.l), although some reversibility may and does occur.

NWFP are obtained from all these types of forested land. It is frequently reported that more products are obtained from secondary than from primary forests. This may be due to some intrinsic properties of secondary forests (predominance of some pioneer species of interest) or may be the result of enrichment. However, it could also be a tautology reflecting the fact that people obtain more products from nearby areas and that, by so doing, these areas are transformed to secondary forests, or it may simply retlect a community's limited access to primary or lessdisturbed forests. Often primary forests may yield fewer products but still be the main supplier/reservoir of key, highly valued products.

Figure 1: Evolution of forest - woodland ecosystems

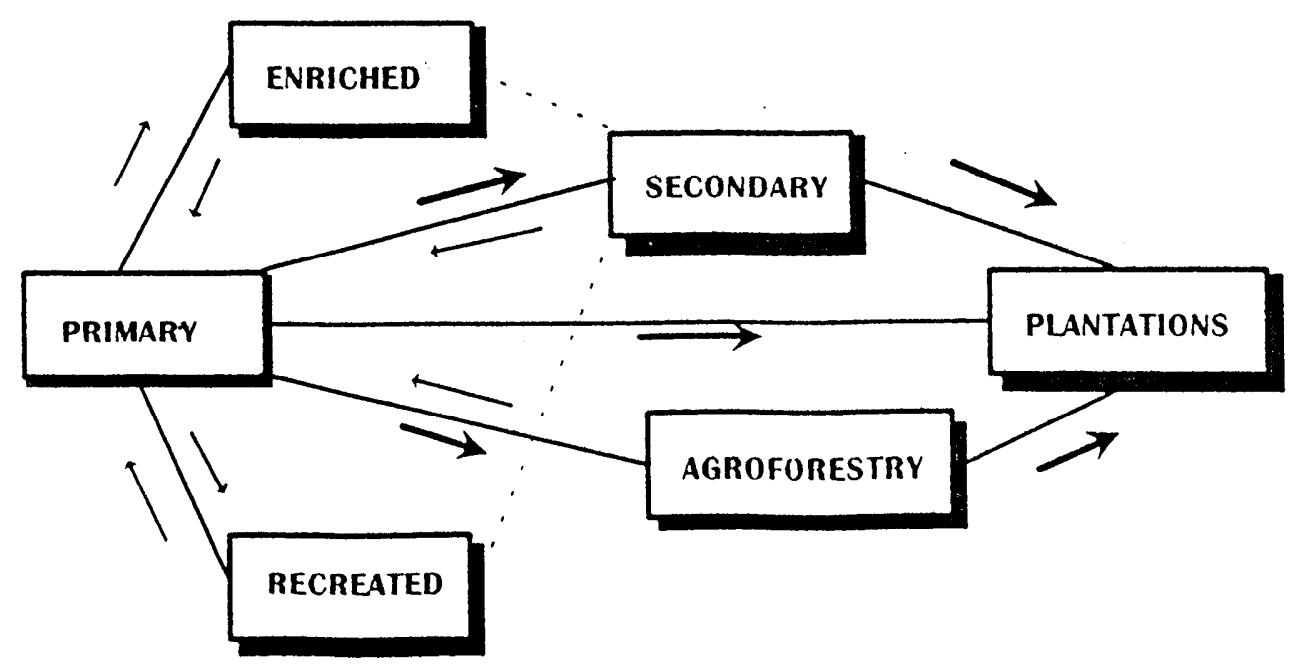


This dynamic axis is relevant because regional land-use planning will have to combine, in a mosaic, all types of areas from pristine, low-disturbed forests to secondary forests in different stages of succession, tree plantations, agroforestry, pasturelands and intensive agriculture. The potential of systems producing NWFP and their environmental values will thus have to be assessed in the light of this trend.

Some relevant questions that ought to be posed in a research framework are:

- How and why are forests evolving in a certain region?

- How does this evolution affect the availability/sustainability of NWFP? How does extraction of NWFP affect the forest and its main environmental functions (biodiversity, soil, water ...)?

- Which species are used to obtain a specific product? Are some species better than others?

- Availablity of a certain product from forests with different degrees of intervention?

Some hypotheses to test are :

- The trend is to produce NWFP in more anthropogenic types of forest (cost efficiency, labour saving, guaranteed quantities).

This trend represents a better option for the conservation and sustainable management of natural forests.

- Certain products - some mushrooms, medicinal plants and game - would mainly be obtained from little-disturbed forests (for biophysical and socioeconomic reasons)

- Extraction of NWFP does not Significantly affect forest structure and functions.

\section{Non-market - market dynamics}

Markets can play a major role in extractive economies and although many NWFP do not enter the market system, they are also influenced by labour demand, use of shared facilities, potential substitution, etc. The main factors affecting the market supply of NWFP are: uneven, irregular yields (both in quantity and quality); seasonality; distance to markets and transport facilities; marketing channels; physical properties of the product (perishability, possibility to process and preserve); and price. The alternatives for the producer's/collector's labour will influence willingness to participate in production.

The demand is also affected by price and product quality, as well as by product replacement (either by a natural or synthetic substitute) and income. Moreover, consumer traditions and fashions (and a belief in helping to conserve tropical forests by buying certain NWFP) play a significant role in NWFP markets, particularly at an international level.

Frequently, one or a very few products play the role of "Backbone" or "Attractor" for the rest, articulating the extractive economies and supporting the market around them. Durian, rattan and bamboo in South East Asia, gum arabic in East Africa, palm wine and wild mango in West Africa, or Brazil nuts, rubber and aguaje fruits if the Western Amazon are examples of these. When the backbone product for a certain situation disappears (due to lack of demand or over-exploitation), it affects the whole range of activities and market relations, forcing their reshaping or eventual collapse.

The extremes of this axis can be represented by products that are gathered for home consumption without entering the market (some food and medicinal plants, house-building materials and game) to products that are mainly or exclusively meant for the international market (gum arabic, chicle and some other plant exudates, or bird nests). Local, regional and national market demands are intermediate situations between those extremes. Most products may occupy several positions on this axis, being homeconsumed and sold at different market levels. The predominance of one position or another may change with Theoretical frequency curves of products along the market levkls could follow negative slopes (Fig. 2). 
Figure 2a: Theoretical frequency curves of products along market levels
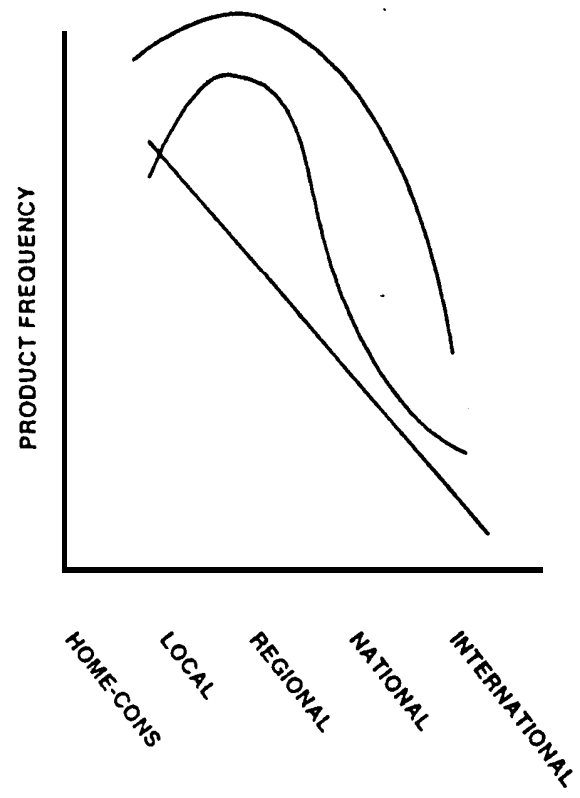

Markets for NWFP are difficult to develop and maintain, and the predictability of their evolution is generally low. It could be argued that most products used for home consumption or sold at local or regional markets tend to stay in those positions for long periods, whereas few products have enjoyed a longlasting presence in the international market. Most internationally marketed NWFP are subject to boom-and-slump cycles with some eventually disappearing, with product substitution playing a major role. A corollary to this situation is that new technologies and demands have a strong impact on the emergence of new products, which makes the NWFP markets very dynamic. On the other hand, local markets tend to be thin in the sense that small variations in the supply have large effects on prices.

Some relevant questions related to the dynamics of this axis are:

- What is the position of a product at different market levels? How is this position changing?

How has the quantity/quality of a product evolved over time?

- How are marketing channels organised and evolving?
Figure 2b: Market durability and product sut stitution at different market levels

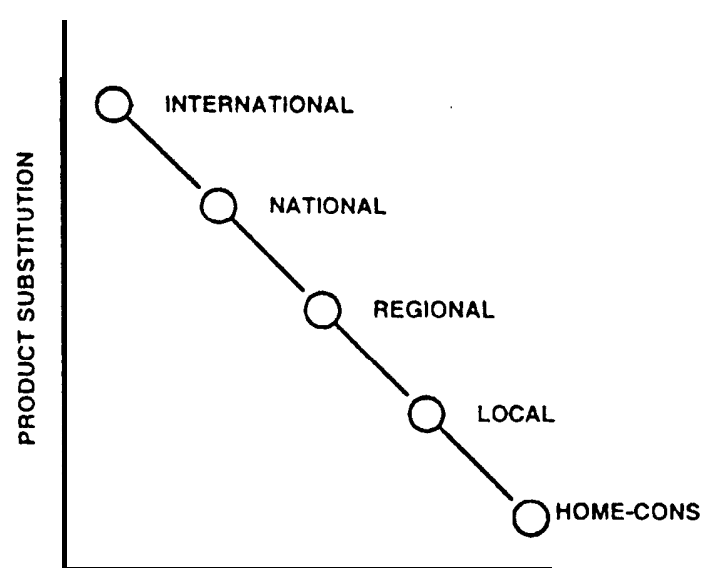

MARKET DURABILITY RESILIENCY

- What are the marketing costs and distribution of profits? What are their trends?

- How is market information organised ? How is it changing?

- Which are the main factors controlling the supply of a product?

- Which are the main factors influencing the consumption/demand of a product?

- What can be said about market elasticities?

Some research hypotheses to test may include:

- Local-level markets are thinner, whereas international markets are more affected by product substitution.

- Product quality and regularity of supply are the main concerns of international markets.

- Green consumers play a significant role in international and some national markets for NWFP.

- Middlemen's disproportionate share of value along the marketing channel is more likely to occur in internationally 
marketed products than in those for local markets, and is related to transport and processing facilities (monopsony versus large number of buyers).

- Eliminating market distortions will result in improved forest management and household income.

\section{Technological changes}

Technology plays a dual role in influencing the use of NWFP. Thus, technological developments at the extraction stage can be essential to improve the sustainable management of forests by changing extraction techniques and allowing for a non-destructive extraction system or extending the productive life of the individual harvested. Similarly, developments in processing and conservation technologies may increase the product availability and market scope, as well as reduce losses. Finally, technologies for market information, consolidation and development can also be important to guarantee the continuation of the activity. On the other hand, technological development can also lead to product obsolescence, eliminating demand by changing to another technology which no longer needs a given product or by replacing natural products with synthetic substitutes. There are two different aspects of the technological dimension: a) production; and b) processing and utilisation.

Improved extraction techniques and ecosystem management, as well as domestication, are technological advances in the production process. Strictly speaking, domestication implies the genetic modification of an species to the point that it can no longer survive in the wild without human intervention. In this strict sense domestication is only achieved after a very long process that includes stages of management of the natural and semi-natural environments and semidomestication. In the past, the first stages of domestication usually were involuntary and later accelerated by more consciously directed intervention. Modern agronomy, forestry and biotechnology have completely changed the situation, having increased the speed of the process by at least one order of magnitude.
Linked to domestication, and also mentioned briefly in the first axis, is the appropriation/recreation of forest structures and processes by rural communities. This habitat modification or "domestication of the environment" is a complement to species domestication.

The modern process of domestication is frequently triggered by unmet demands of markets with potential. This could happen when the product naturally occurs in very low abundance or because, having being abundant, it was exploited in a non-sustainable way that placed the natural populations on the brink of local .extinction. It could also reflect industry needs for improved qualities and new properties. In all cases it is frequently argued that the process of domestication helps improve the management of natural forests. On the other hand, it could also favour forest clearance to establish plantations.

One of the most amazing features of NWFP is that we can still witness the common process of domestication at different stages (from management to plantation) taking place, especially in the tropics. It could be argued that the most successful products will experience an acceleration in the process to complete domestication and removal from wild hunting/gathering. It is more likely that new plants will be domesticated than new animals and, of these, fish probably represent the group with the highest chances. However, most products will never be fully domesticated. The extremes of this axis can be depicted by products that will always be hunted/gathered from the wild (some game, foods, tibers and medicinal plants) to those that are already cultivated away from the forest and are no longer gathered (most internationally traded varieties of tropical fruits). A large number of NWFP, however, will still be obtained from a mix of situations from wild to planted-raised and sometimes domesticated sources. The trend seems to be uni-directional despite the occasional backcrossing with some wild stock (Fig. 3), stressing the need for a better knowledge of taxonomy and to conserve the wild progenitors of important market varieties. 
Figure 3: Trend in the use of species along the gradient from wild to domesticated

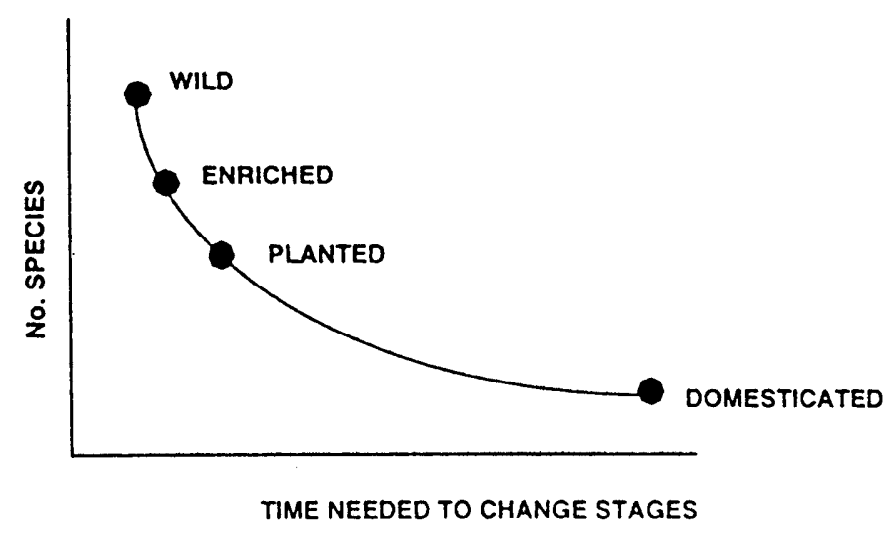

Processing and utilisation is the other main aspect of technological change. One extreme of this gradient could be marked by products such as fruits that are consumed next to the place where they are collected without any further transformation. (It could be argued that knowing the properties of the product represents already a certain technological development, particularly for some medicinal plants.) Other extremes with high technological development are represented at the processing and/or conservation levels (some oils, extracts, medicines or fruits). The prevalent trend along this axis would be to move from low to high technological input if it is still extracted or to synthesis and product replacement (see Fig. 4).

Figure 4: Possible relationship between technology improvement and substitution

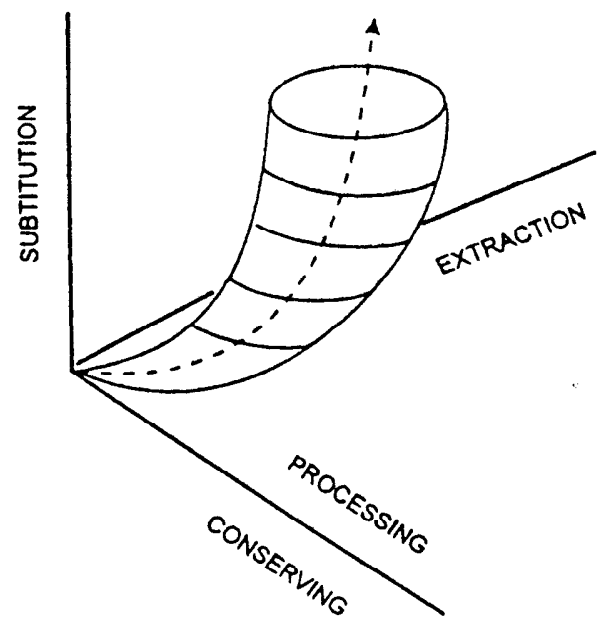

Along this gradient, some products will be obtained and processed with different levels of technological development. Awareness of the conditions that allow the same product to be obtained with different technological sophistication is a key to appropriate direction 
of development and policy efforts. In this sense, extractivism, far from being considered a backward activity from which to be redeemed, could well be considered as an intermediary between biodiversity and biotechnology, thus dramatically changing the social appreciation of the activity (see Fig. 5).

Figure 5: Extractive activities as intermediaries between biodiversity and biotechnology

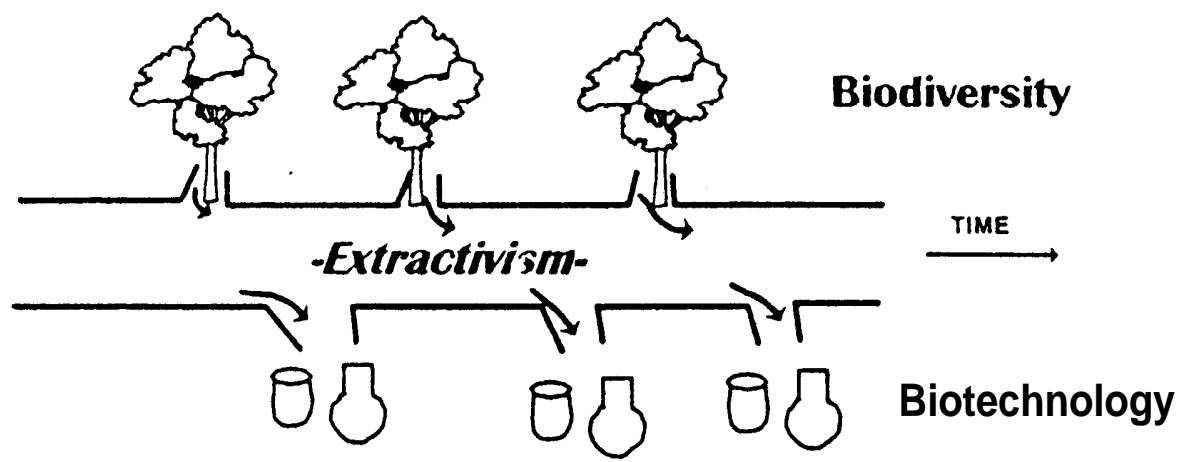

Questions concerning processing and utilisation may include:

- What are the extraction/management techniques? How can they be improved?

- Is the species in the process of domestication (management, semi-natural stage)? If so, what is promoting it?

- Which biological features promote/hinder management and/or domestication?

- Is the new technology leading to NWFP promotion or abandonment?

- Who drives the technological change (producer, processor, consumer, industry not directly linked to NWFP)?

- What are the reasons behind that change (increase quantity, improve quality, improve availability, reduce costs, ...) ?

- How is it affecting forest management, . markets, household income?

- Which policies favour/impede it?

- Why are improved technologies already tested not widely used?
Some hypotheses to be tested are:

- The process of domestication will inevitably lead to the abandonment of wild extraction.

- Product depletion and the existence of markets are the leading forces for domestication.

- In some conditions (specify) management is better than domestication.

- Markets differentiate between wild and domesticated products.

- Technological change will make some NWFP obsolete (to identify them).

- Technological change will offer new opportunities for some NWFP (to identify them).

- Technological change will improve forest conservation and management.

- Technological change will improve household income and labour efficiency.

- Technological change is basically processor/industry driven.

- The adoption of new technologies depend on market demands and capital availability. 


\section{La bour-household economy}

Very few communities of hunter-gatherers depend exclusively on the consumption of NWFP for their survival. Similarly, few extractive communities or households depend exclusively on selling It could be said that in almost all households or communities that obtain NWFP these represent a part-time (though sometimes dominant) activity whose full value (use plus exchange) represents a part (sometimes the majority) of the total wealth of the household or community.

From this perspective, NWFP can be considered as part of a strategy to diversify and maximise the returns to labour and income, to minimise risks and to obtain resourcesin areaswith unclear or unfavourable land-tenure situations. The low labour input required to maintain the system (not necessarily to obtain the resources) as opposed to the high labour input for agricultural activities, together with the usual seasonality of most NWFP, makes them an excellent complement or buffer in areas of high risk, even if agriculture is the predominant activity.

NWFP are also opportunities for social group specialisation (gender, age, social class or caste). In some cases households (more rarely communities) specialise in harvesting
NWFP and can move between products in response to market demands. This tends to occur in peri-urban areas with a high demand for NWFP and with close contacts between producers and consumers. The activit (extraction and selling) rather than the product itself is the niche or job specialisation.

There are indications of low remuneration for time devoted to obtaining raw NWFP when compared with the income from traditional agricultural activities, although this situation varies between places and products. When this is not the case, seasonal or other physical restrictions may prevent a higher dedication to the activity On the other hand, this remuneration is significantly increased when processin gis carried out in the same household/community For this reason processing/adding value at the local level is one of the key policy issues for NWFP. In some cases however, technological, transport or financial requirements may act against such value-adding activity.

A variety of situations can be found along this axis, from low to high remuneration and allocation of labour, and from a marginal to a predominant situation in the household economy (Fig 6). The "threshold " is mainly determined by the best available alternative use of household resources and time.

Figure 6 :Viability threshold related to income and labour intensity

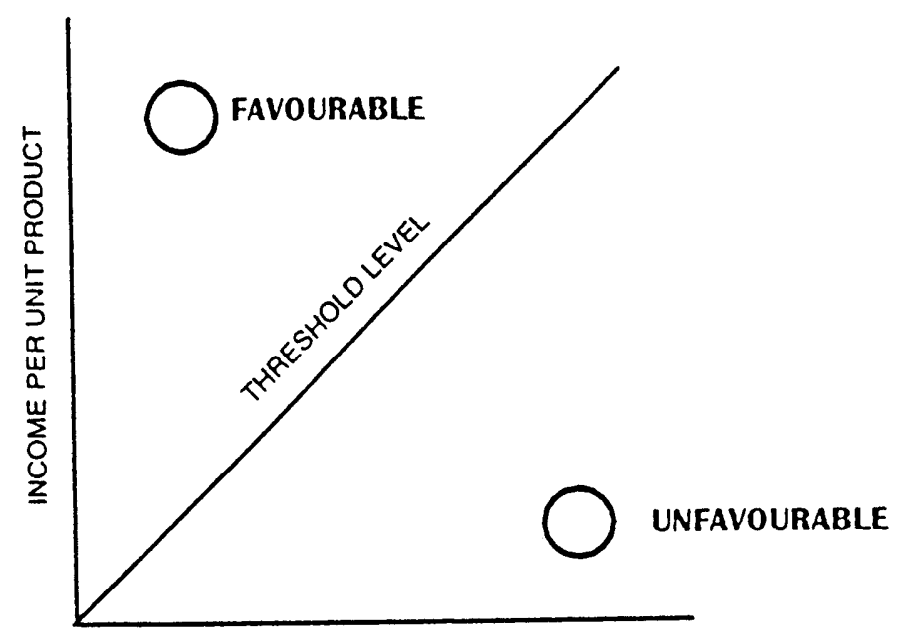

INTENSITY OF LABOUR 
Questions related to the dynamics of this axis are:

- What is the proportion of time needed to obtain NWFP (home-consumption and market)? How has it evolved?

- What is the community/social oroup/household specialisation? How has it evolved?

- What is the land tenure situation? How is it evolving?

- What is the share of NWFP in household income? How has it evolved?

- What are the complementarities between food crops and NWFP at a household level?

- What is the profitability and return to labour and how do these compare with the returns from other household activities?

- At what level of remuneration does an activity/product appear or disappear?

- What has been the transition in local communities previously highly dependent on NWFP?

- How is value added?

- Is there any trend to increase locally added value? What promotes/precludes it?

- Are externalities being recognised?

Research hypothesis to be tested:

- NWFP are collected by specialised social groups.

NWFP are less remunerative of labour than agricultural commodities.

The trend is to abandon products with low value per unit of labour.

Securing user rights/land tenure is a precondition for long-term production investment and household development.

Loca I processing can significantly increase the value added and represents a more profitable? opportunity for labour.

Increasing value added at the local level depends on technology and capital availability.
5. People's perceptions, preferences and opportunities cultural dynamics

A prevalent view of technology and social progress considers gathering and consumption of NWFP as a backward activity with low social status. Yet, many people in rural areas maintain this activity and even fight for clearer rights to continue these traditions. In fact those rights, centred around land tenure, are one of the key points in all the agendas of forest-dependent people. Thus, understanding people's motivations to pursue this activity is essential for policy proposals and development actions.

Bearing in mind that NWFP collection is normally a part-time activity that constitutes one part of a broader strategy, the reasons why people extract and consume NWFP are varied. They reflect household livelihood in different ways, linked to the availability of resources, the remuneration for labour, risk aversion, other options available and cultural attitudes.

They could be summarised in four main categories:

1) better options are not available (caused by lack of access to resources like training, land or capital; "buying time" strategy);

2) better options exist but they are unknown (caused by lack of information);

3) well-integrated with other activities (good remuneration for labour and availability of resources; diversification and access to resources strategy);

4) intrinsic element of their whole social and cultural identity (group coherence, cultural and political strategy).

These four groups define the spectrum of the axis, and could be represented by an individual/community aspiring to own land to become farmers (I) or looking for options in other sectors of activity (2), by mixed farming systems where agroforestry-extraction is an essential component of their whole economic activity (3) or by an indigenous group wanting to maintain its ancestral territory and traditional activities (4) (see Fig. 7). The expected trends within each group would be for the first two to be changed for another option when available, for te third to be maintained in a highly dynamic (productwise) situation. and for the fourth to persist in a less dynamic (product-wise) situation. 
Changes in culture and formal education will influence these trends.

The implications for each of the main categories are radically different, since people might be looking forward to leaving the activity, or to reinforce it if improvements/ incentives are provided. The identification of those improvements/incentives (related to land tenure, market organisation, transport, extraction, preserving and processing technology, general social infrastructure, etc.) is also an essential part of research aimed at policy and development proposals.

Figure 7: Policy actions related to people's preferences

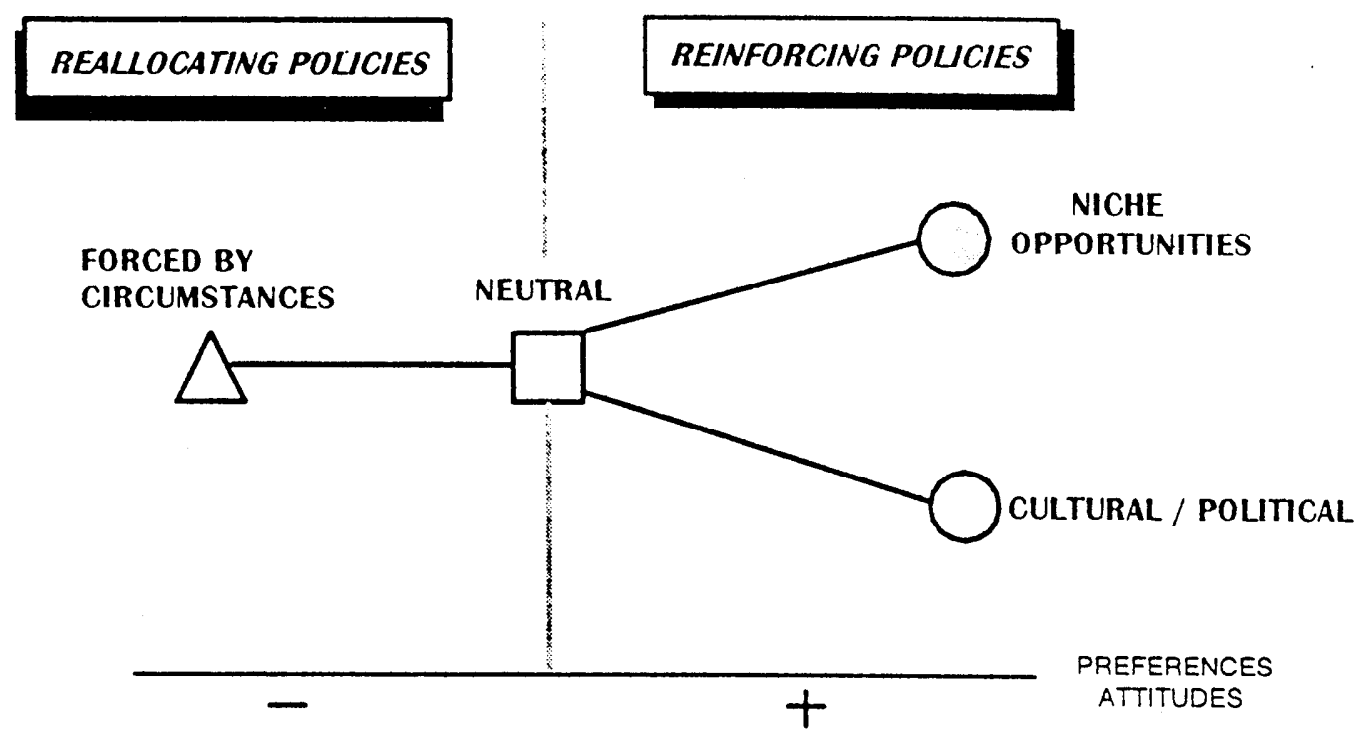

Finally on this axis it is also important to identify the cultural trends at a general level that influence the production-consumption of NWFP. The above-mentioned view of a "backward activity", together with the widespread pressure to change to foreign patterns of consumption, may have a detrimental effect on continuation of these activities. On the other hand, the "green vogue", the saturation of some conventional markets, the trend to recognise potential positive environmental externalities and the increasing self-esteem of communities carrying out traditional activities, may encourage their maintenance.

Thus, relevant questions about this dimension may include:

- What makes a certain extractive activity/product resilien/prone to change?

- How are people (both producers and consumers) reacting to these changes?
- Are there other known options? How do they interrelate (complementary, competing, exclusive)?

- How do people perceive themselves with regard to those options?

- What are the priorities perceived by forest dependent people?

- W'ich are the local institutions that regulate access and use of NWFP?

- What is the role of NWFP in people's economic strategies?

- What is the cultural attitude of producers/consumers towards NWFP?

- How is this attitude changing and what is promoting the change? 
Some hypothesis to test are:

- Household/community wants to keep extracting/using NWFP.

- There are better options but they are unknown.

- Better options are not available.

The predominant cultural attitude prefers to replace NWFP and extractive activities by conventional agricultural commodities and activities.

Training and educational campaigns can intluence this attitude,

\subsection{Policy development}

Being a very dynamic issue with a generally weak economic and social position, direct and indirect policies have a strong influence on NWFP. In general terms, in recent times there have been few direct policies or regulations aimed at NWFP. The most frequent one is the need for specific NWFP management plans as part of a broader request for forest management plans. However, they are very rarely developed and even more rarely implemented. Some trade policies, taxes and subsidies are also directly targeted at NWFP. On the research side, there is a growing interest on NWFP but the work is still very marginal compared to the whole forestry research field, which, at the same time, only represents a fraction of total study into agriculture.

Current indirect policies are probably the ones having a stronger, often unintentional, effect on NWFP. These relate to issues like land tenure and agrarian reform, policies towards complementary-concurrent products, population, nature conservation, public participation, social equity, general transport and other infrastructural policies, industrial policies, macroeconomic policies, taxes and incentives. Their inter-sectoral links, synergisms or off-setting of their effects on NWFP are essential to understand. Additionally, some international policies (trade, monetary, nature conservation, etc.) may also have major - normally indirect effects on NWFP.
Fig. 8 shows the range of variation within this dimension. It could be argued that the future evolution of policies directed at NWFP will tend to give emphasis to national direct policies and to international indirect ones in a broader frame where the incorporation of externalities will play a significant role. These aspects are particularly important for a centre like CIFOR, with a worldwide mandate focused on research whose results will encourage appropriate policy changes.

Questions relevant to this axis may include:

- Who are the main stakeholders? How do they organise? How have they evolved?

- What are the main issues in forestdependent people's agendas? How are they being faced by governments?

- Which are the customary rules that need to be incorporated into public policies and laws?

Which are the direct policies towards NWFP? How are they being implemented and by whom?

How are these policies evolving?

- Which are the indirect policies affecting NWFP? How do they affect them? How are they evolving?

What are the institutional settings of these poiicies? How are they evolving?

a Which are the links (contradictory or reinforcing) between local, national and international policies affecting NWFP?

Research hypotheses could include:

- Major economic, trade and environmental policies have a significant effect on NWFP.

There is a trend to explicitly incorporate NWFP in national policies.

- This trend will have a positive effect on the sustainable extraction and use of NWFP (to check for each policy, i.e., land tenure, population, public participation, social equity, trade, tax, e(c). 
Figure 8: Policy effects and trends at different levels

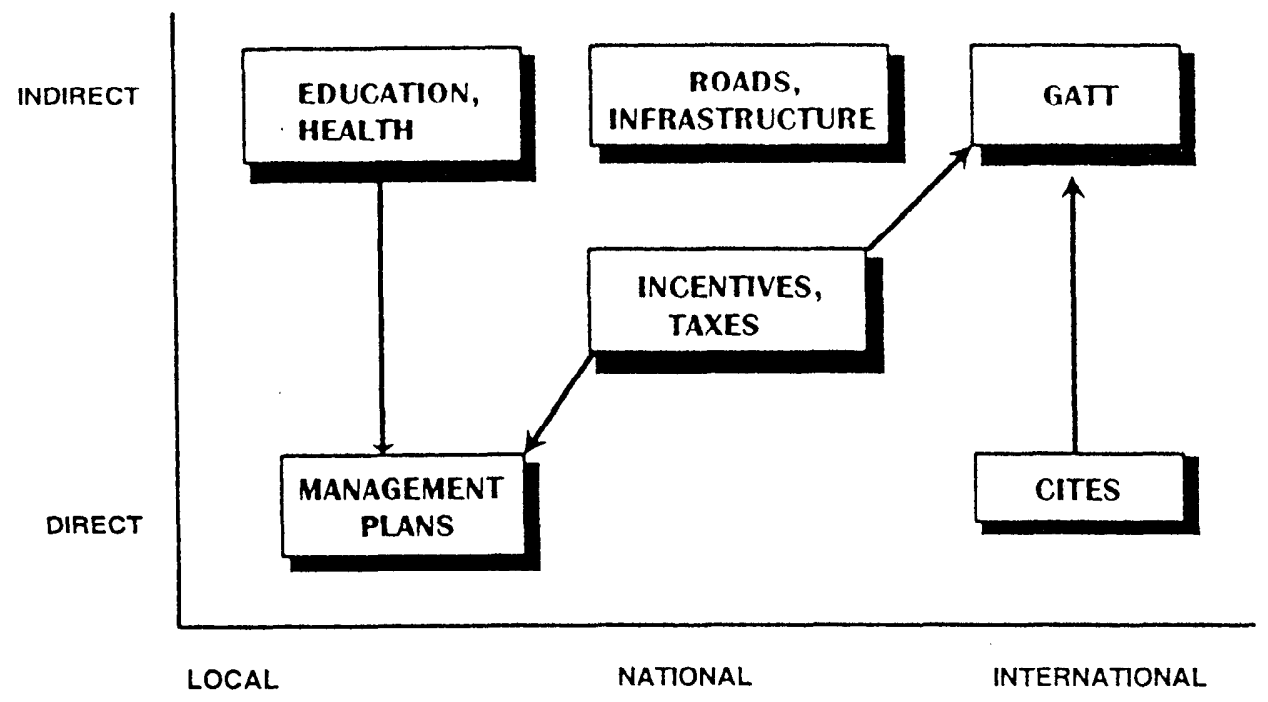

\section{The "Bicycle Model", a hypothetical model of the global trend of NWFP}

Although a global model of extractive economies is still far from reality, I propose here a hypothetically possible general trend that could reflect the future role of NWFP. The intention is to provoke thought and trigger further discussion.

A likely scenario is that NWFP will follow a similar path to that of the bicycle, which was the major way of daily transport all over the world until a few decades ago. With the expansion of the car industry, the bicycle was almost forgotten in the developed world, though it continued to be very much used (and still is) in developing countries as one of the main daily transport systems available.

However, the environmental problems brought on by the proliferation of cars, full transport and fuel cost policies, the availability of special lanes for bicycles that make them safer and quicker, and a new attitude towards physical exercise and leisure have brought a complete change in the situation. Nowadays, it could be argued that most households in developed countries have bicycles for daily or weekend/holidays use. These play a multiple role, linked to their former function (quicker than a pedestrian) but also to their social, leisure and new link with nature roles. In the developing world the bicycle still plays the dominant role of being the quickest means of affordable transport. So what was once considered to be an indicator of backwardness to be replaced, is now perceived as one of the symbols of a new style of life.

Could NWFP be in a similar position in the future? The trend towards green markets, their perception (to be demonstrated) as a better way of managing natural forests, a new cultural attitude, and the slow but steady incorporation of NWFP in professional (teaching and research) curricula seems to indicate such a possiblity. Perhaps the future role of NWFP will be a renewed, multifunctional one not only linked to their physical properties but also (and sometimes mainly) to the social, cultural and environmental attributes that are/will be in a phase of expansion, as shown in Fig. 9, where the width is proportional to the number of socially appreciated attributes Helping to accelerate this process might be one of the main contributions and challenges of CIFOR. 
Figure 9: Hypothetical general trend for NWFP

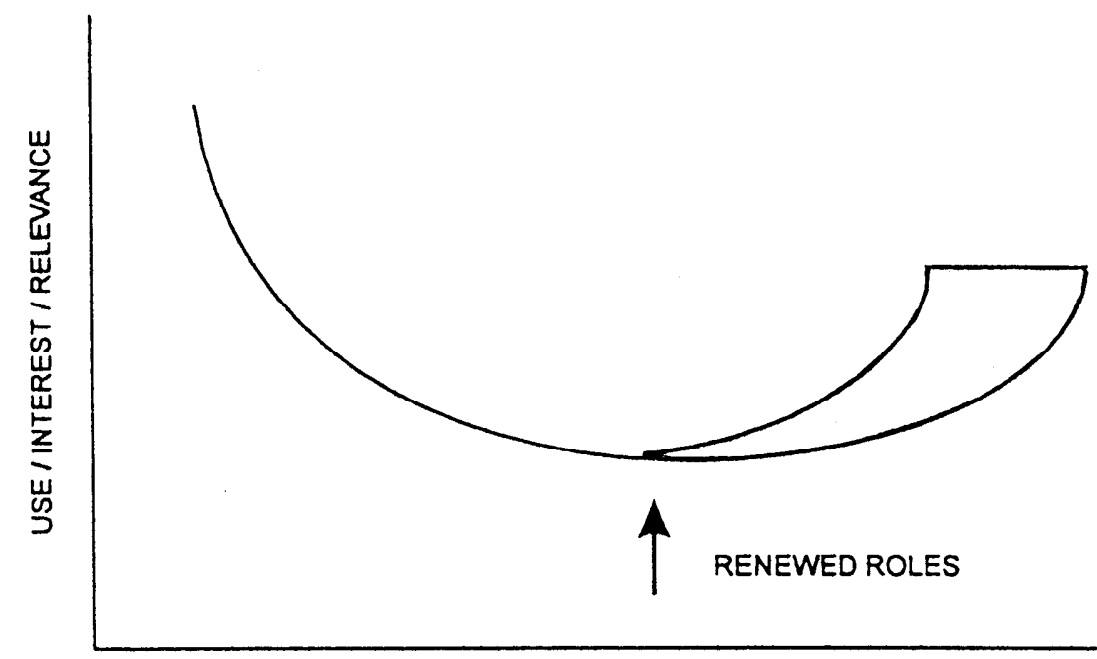

TIME

\section{References}

Anderson, A.B. (Ed.). 1990. Alternatives to Deforestation. Steps Towards Sustainable Use of the Amazon Rain Forest. Columbia University Press. New York.

Balée. W. 1989. The culture of Amazonian forests, Advances in Economic Botany', 7: 1-21.

Bossel, H. and Bruenig, E.F. 1992. Natural Resource System Analysis. Ecological and Socioeconomic System and Sensitivity Analysis for the Conservation and Management of Forest Ecosystems and Natural Resources in South-East Asia. DSE. Feldafing (FRG).

Botkin, D.B. 1993. Forest Dynamics. An Ecological Model. Oxford University Press. Oxford and New York.

Burkill, I.H. 1935. A Dictionary of the Economic Products of the Malay Peninsula (2nd edition, 1966). Ministry of Agriculture and Co-operatives. Kuala Lumpur.

CATIE. 1992. Informe final Proyecto Conservación para el Desarrollo Sostenible. Fase 1. Unpublished report. CATIE. Turrialba. Costa Rica.

- de Beer, J.H. and McDermott, M.J. 1989. The Economic Value of Non-Timber Forest Products in South East Asia. IUCN-Netherlands. Amsterdam.

de Wit, H.C.D. 1994. Karel Heyne and his classic on economic plants, PROSEA Newsletter, Special issue No. 1.

Falconer, J. 1990. The Major Significan e of "Minor" Forest Products. The Local Use and Value of Forests in the West African Humid Forest Zone. Community Forestry Note 6. FAO. Rome.

Falconer, J. and Arnold, J.E.M. 1989. Houschold Food Security and Forestry. An Analysis of Socioeconomic issues. Community Forestry Note 1. FAO. Rome. 
Godoy, R.A. and Bawa, K.S. 1993. The economic value and sustainable harvest of plants and animals from the tropical forest: assumptions, hypotheses and methods. Economic Botany, 37(3): 2 15-2 19.

Godoy, R., Brokaw, N. and Wilkie, D. 1994. The effect of income on the extraction of non-timber tropical forest products by indigenous people: model, hypothesis and preliminary findings from the Sumu Indians of Nicaragua. IUCN General Assembly. Workshop 3: Sustainable Use of Living Natural resources. Buenos Aires. January 1994.

Gunatilakc, H.M. 1994. Factors influencing peripheral villager dependency on forest resources use in the Knuckles Forest Range. Sri Lankan Journal of Agricultural Economics, 2(l): 7-21.

Hames, R. and Vickers, W.T. (Eds.). 1983. Adaptive Responses of Native Amazonians. Academic Press. New York.

Homma, A.K.O. 1990. Extrativismo Vegetal C a Solucao para a Amazonia?. Symposium "Ecologia e Agricultura Sustentavel en Biomas Brasileiros". Academia Brasileira de Ciencias. Rio de Janeiro. February 1992.

Homma, A.K.O. 1992. The dynamics of extraction in Amazonia: A historical perspective. Advances in Economic Botany, 9: 23-32.

King, J.L. and Kraemer, K.L. 1993. Models, facts and the policy process: the political ecology of estimated truth. In: Goodchild, M.F., Parks, B.O. and Steyaert, L.T. (Eds.). Environmental Modeling with GIS. Oxford University Press. New York, Oxford.

Lescure, J.P. (Coord.) 1993. Les activites extractivists en Amazonie Centrale: une premiere syntheses d'un projet multidisciplinaire. ORSTOM ANPA. Paris. Unpublished report.

Peluso, N. L. 1992. The political ecology of extraction and extractive reserves in East Kalimantan, Indonesia. Development and Change, 23(4): 49-74.

Pereira, H.S. 1992. Extrativismo e Agricultura: as escolhas de una comunidade ribeirinha do MCdio Solimdes. Post-graduate Thesis. INPA-Universidade do Amazonas.

Ruiz Pérez, M., Sayer, J.A. and Cohen Jehoram, S. (Eds.) 1993. El Extractivismo en Amkrica Jatina. UICN. Gland.

Salafsky N., Dugelby, B.L. and Terborgh, J.W. 1993. Can extractive reserves save the rain forest? An ecological and socioeconomic comparison of nontimber forest product extraction systems in Peten, Guatemala, and West Kalimantan, Indonesia. Conservation Biology, 7(1): 39-52.

Townson, I.M. 1994. Forest Products and Household Incomes. A Review and Annotated Bibliography. Draft mimeo. Oxford Forestry Institute. Oxford. 